\title{
Wind Turbine Speed Compound Control of a New-Type Wind- Electric Hybrid Power Pumping Unit
}

\author{
Chunyou ZHANG*, Lihua WANG
}

College of Engineering, Inner Mongolia University for Nationalities, Tongliao, China

*Corresponding Author: Chunyou ZHANG, E-mail: zcy19801204@126.com

\begin{abstract}
:
Because the load of the oil beam pumping unit driven by pure electric motor changes sharply during operation, the power of the driving motor does not match and the energy efficiency is low. In this paper, a new type of wind-driven hydro-motor hybrid power system is proposed. The motor and the hydraulic motor are jointly driven, and the energy is recovered by a hydraulic pump with controllable displacement, so that the speed of the driving motor is relatively stable. In order to control the fan speed and keep up with the drastic changes of the outside wind speed, a control strategy of hybrid power system based on wind speed feed-forward compensation is proposed. Through simulation and experimental results, the following conclusions can be drawn: to begin with, the mathematic model is proved to be effective; next, simulation studies show that the proposed feed-forward control method can improve the response rate as well as reduce the response lag. This research can be a reference for the application of the feed-forward control method on the hybrid power system of beam pumping unit.system.
\end{abstract}

Keywords: beam pumping unit; hydraulic-motor hybrid system; feed-forward control method; Fuzzy-PID control

\section{Introduction}

Beam pumping unit is the most widely used engineering machineries in the petroleum production industry ${ }^{[1]}$. In order to periodically drive the pumping operation, the traditional method is using electromotor to directly drive the crank ${ }^{[2]}$. Due to the particularity of the oil rod job, the mechanical load characteristics of the driving unit are periodically and drastically changed ${ }^{[3]}$, which makes the efficiency of the whole power system relatively low. The most recent studies on the power system of beam pumping unit mainly focused on the beam unit structure optimizations and control motor selection. Dong et al ${ }^{[4]}$ simulated the dynamic performance of the beam pumping system, and the comprehensive optimization algorithm is proposed in order to improve the operation speed. Gibbs ${ }^{[5]}$ declared that electrical predictions can be used in the mechanical models of oil pumping system. Lv et al ${ }^{[6]}$ proposed an energy saving system for a beam pumping unit based on four types of networking sensors. However, structure optimizations can hardly change the operation mode of the beam unit. Moreover, control regulation and component selection can not in principle avoid the power mismatch problem of the drive motor. Therefore, the efficiency of the traditional direct-drive method is low, and the operational reliability is bad.
Recently, more and more researchers have focused on the study of the wind speed following control. Li et al ${ }^{[7]}$ proposes a wind speed predictive method by neural network, and they improve the ability of small wind power generation system to capture wind energy by robust control of maximum power extraction for potential drift of wind turbine power coefficient curve. Soufi et al ${ }^{[8]}$ proposes a particle swarm optimization method based on feedback linearization control in order to study the maximum power point tracking control (MPPT) of wind power generator set. In their research, the maximum wind energy absorption is the goal to achieve the maximum wind energy capture. However, the accuracy of the control methods can not be proved. Because the wind wheel machine belongs to system of large inertia and large lag, error of the traditional control method is large. Based on variable speed constant frequency wind power system, Ren et al ${ }^{[9]}$ put forward the method of feed-forward and feedback control strategy for variable pitch control which can realize the constant power output above the rated wind speed. Chen et al ${ }^{[10]}$ study the MPPT control strategy based on permanent magnet synchronous wind generator, and the MPPT control of wind wheel is realized by adjusting the on-line control parameters with feed-forward controller. Abo-Khalil et al ${ }^{[11]}$ also research the wind power generation system based on doubly-fed 
induction generator based on controlled MPPT by using feed-forward and feedback. Liang ${ }^{[12]}$ et al propose a feed forward transient compensation (FFTC) control scheme based on doubly-fed induction generator with proportional integral resonant current regulator in order to enhance the low voltage crossing (LVRT) capability and adapt to unbalanced power grid faults. Verwaal ${ }^{[13]}$ et al develop a more reliable wind speed measurement method to enhance the control performance of wind turbine by implementing feed-forward related control strategy. These studies all carry on the application of advance control method on the wind wheel power system. However, the studies mainly focus on the control method on the pumping unit with direct driven motor.

This paper proposes a new type of hydraulic-motor hybrid power system for the beam-pumping unit, and a new feed-forward control method. The principle of the hybrid power system is proposed, and the mathematical model is set up which is verified by experiment studies. In addition, the results of the feed-forward control on the hybrid power system of the beam pumping unit are compared with the traditional PID method.

\section{Modelling and experiment}

2.1 Configuration of the new kind of wind power hydraulic-motor hybrid power system of the beampumping unit

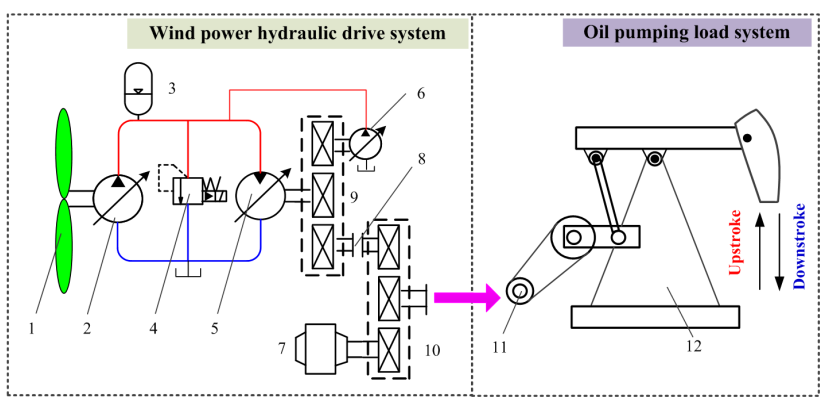

Figure 1 Structure of the oil pumping drive system based on wind power hydraulic

(1). Wind wheel. (2). Controlled hydraulic pump A. (3). Energy accumulator. (4). Relief valve.(5). Controlled hydraulic motor.

(6). Controlled pump B. (7). Electrical motor. (8). Clutch.(9).

Torque meshing gear group A. (10). Torque meshing gear group B.(11). Load shaft. (12). Beam pumping unit.

A new-kind of wind power hydraulic-motor hybrid power system special for beam pumping unit is designed, and its configuration is illustrated in figure 1. Structure The oil pumping drive system mainly consists two parts: one is wind power hydraulic drive system, and the other is oil pumping load system. The wind power hydraulic drive system is the main part and is mainly composed of a wind wheel, two discharged controlled hydraulic pumps, a controlled hydraulic motor, two meshing gear groups, an energy accumulator, and an electrical motor. The oil pumping load system is similar to the traditional beam pumping unit, which means this designed power system is common to the general beam pumping unit.

Main power source of the system is wind power, and it is directly gathered by the wind wheel. The rotating wind wheel drives hydraulic pump A, and then generates high pressure at the upstream side of the hydraulic motor. Both the torque meshing gear groups have three intercoupled gears. In addition, one of the three gears couples the torques of the other two gears, and it is called the sum gear. When hydraulic motor is driven, sum gear A drives the other two gears. One of the gears outputs torque to controlled pump B, and the other provides power to torque meshing gear group B. In order to avoid the lack of power of the system, an electric motor is added in controlled pump B as the torque compensation unit. Sum gear B directly drives load shaft of the oil pumping load system. What is more, the controlled pump B and the hydraulic accumulator can recycle excess energy from the load system when the sum gear B is over torqued.

According to figure 1, one working cycle of the beam pumping units mainly consists of up stroke and down stroke of the horse head. In addition, working cycles of the beam pumping unit and drive load shaft are synchronous. In another word, a circle work of sum gear B includes two working strokes of the beam pumping unit.

As is mentioned above, motor which directly drives the load shaft of the beam pumping unit will work at a relatively low efficiency. That is because during the start process the drive motor needs a very high power to put the beam pumping unit in motion, however when the unit keeps working regularly, the motor needs a relatively low power which is approximately half of the start power, and that will lead to a great mismatch of the engine power, which will result in a poor efficiency of the motor. This paper provides a method that uses wind power as the main power source, and the designed motor is applied as the auxiliary power supply. This kind of setting can avoid the motor working at a power which is far away from the rated power, and then avoid the inefficiency of the motor.

When the beam pumping unit works at the down stroke process, geopotential energy of the horse head rapidly transforms into kinetic energy. That will lead to prompt acceleration of the rotating speed of motor rotor, and motor will reversal which can interference the motor control. Another unique feature of the designed hybrid power system is that during the down stroke process of the beam pumping unit, through the torque meshing gear groups a large part of the kinetic energy of the horse head will transform to the output hydraulic energy of controlled pump B, and the accumulator will store the energy and then leave it to the upstroke process, which achieves energy recovery.

\subsection{Modeling of the working process}

According to the structure of the designed wind power hydraulic-motor hybrid system, mathematical model of the dynamic working process is built as follows.

2.2.1 Dynamic model of the wind rotor

According to the previous research ${ }^{[15]}$, when the wind speed 
is at a certain value, speed of the wind rotor has an optimal point which can keep the highest wind energy efficiency. In order to obtain as much wind power as possible at a certain wind speed, this paper assumes that the wind rotor is controlled within an interval of precision that can get an optimum tip speed ratio. The dynamic equation of the wind rotor is as shown in Eq. (1):

$$
J_{\mathrm{w}} \dot{\omega}=T_{\mathrm{w}}-T_{\mathrm{P}}^{\prime}-T_{\mathrm{fw}}-B_{\mathrm{w}} \omega
$$

where, $J_{\mathrm{w}}$ is inertia of the wind rotor, $w$ is rotating speed of the rotor, $T_{w}$ means the fan torque, $T_{\mathrm{p}}{ }^{\prime}$ is the restoring torque of the hydraulic pump, $T_{\mathrm{fw}}$ is coefficient of mechanical friction, and $B_{w}$ is viscosity coefficient. The restoring torque of the hydraulic pump $T_{\mathrm{p}}$ ' can be precisely controlled, and then the rotating speed of the wind rotor can be controlled to keep the rotor working at the best state. 2.2.2 Equations of the hydraulic pump

In this hydraulic system, there are two hydraulic pumps with the same working principle. The equation of the restoring torque of the hydraulic pump $T_{\mathrm{p}}$ ' is as follows:

$T_{\mathrm{P}}^{\prime}=i \cdot T_{\mathrm{P}}=i \cdot\left(\Delta p \cdot D_{\mathrm{P}}+J_{\mathrm{p}} \dot{\omega}+B_{\mathrm{p}} \omega\right)$

where, $i$ is transmission ratio of the speed increaser, $T_{\mathrm{p}}$ is drive torque of the hydraulic pump, $\Delta p$ is pressure difference between the inlet and outlet of the pump, $D_{p}$ is displacement of the pump, $J_{p}$ is rotational inertia of the pump, and $B_{\mathrm{p}}$ is viscous friction coefficient of pump shaft.

Flow equation of the hydraulic motor can be described as:

$q_{\mathrm{p}}=D_{\mathrm{p}} \omega_{\mathrm{p}}-C_{\mathrm{ip}}\left(p_{\mathrm{h}}-p_{1}\right)-C_{\mathrm{ep}} p_{\mathrm{h}}-\frac{V_{\mathrm{P}}}{\beta_{\mathrm{e}}} \frac{d p_{\mathrm{h}}}{d t}$

where, $q_{\mathrm{p}}$ is the output flow of the pump, $w_{\mathrm{p}}$ means the rotating speed of the pump, $C_{\mathrm{ip}}$ and $C_{\mathrm{ep}}$ respectively are internal and external leakage parameters, $p_{\mathrm{h}}$ and $p_{1}$ are pressures on the high and low sides of the pump, $V_{\mathrm{p}}$ is displacement of the variable pressure pump chamber, $\beta_{\mathrm{e}}^{\mathrm{p}}$ is the effective bulk modulus of hydraulic oil.

\subsubsection{Equation of the hydraulic motor}

Similarly, the equation of the hydraulic motor can be obtained as follows. The flow of the hydraulic motor $q_{\mathrm{m}}$ is:

$q_{\mathrm{m}}=D_{\mathrm{m}} \omega_{\mathrm{m}}+C_{\mathrm{im}}\left(p_{\mathrm{h}}-p_{1}\right)+C_{\mathrm{em}} p_{\mathrm{h}}+\frac{V_{\mathrm{m}}}{\beta_{\mathrm{e}}} \frac{d p_{\mathrm{h}}}{d t}$

where, $q_{\mathrm{m}}$ is the output flow of the motor, $w_{\mathrm{m}}$ means the rotating speed of the motor, $C_{\mathrm{im}}$ and $C_{\mathrm{em}}$ are internal and external leakage parameters of the motor, respectively, $p_{\mathrm{h}}$ and $p_{1}$ are pressures on the high and low sides of the motor, $V_{\mathrm{m}}$ is displacement of the variable pressure pump chamber.

\subsubsection{Flow equation of the hydraulic accumulator}

In this system, the hydraulic accumulator is used to recover and store the impact energy in the down stroke process of the horsehead of the beam pumping unit. Characteristics of the accumulator greatly affect the stability of the hybrid system. The flow equation of the accumulator is as follows: $q_{a}=\frac{V_{0}}{n P_{0}} \frac{d p}{d t}$

where, $q_{\mathrm{a}}$ is the flow into the accumulator, $V_{0}$ is the initial volume of the accumulator, $n$ is the air polytropic exponent, and $P_{0}$ is inflation pressure of the accumulator. 2.2.5 Flow equation of the whole system

According to the above equations, the flow formulation of the whole system can be derived as follows:

$q_{\mathrm{pA}}+q_{\mathrm{pB}}+q_{\mathrm{a}}=q_{\mathrm{m}}$

where, $q_{\mathrm{pA}}$ and $q_{\mathrm{pB}}$ is respectively the flow of controlled pump A and B. And it is assumed that the low pressure side of the hydraulic system is 0 , and the effective bulk modulus of hydraulic oil is neglected. Then the flow equation can be obtained as follows:

$D_{\mathrm{pA}} \omega_{\mathrm{pA}}+D_{\mathrm{pB}} \omega_{\mathrm{pB}}-D_{\mathrm{m}} \omega_{\mathrm{m}}+C_{\mathrm{t}} p_{\mathrm{h}}+\frac{V_{0}}{n P_{0}} \frac{d p_{\mathrm{h}}}{d t}=0$

where, $w_{\mathrm{pA}}$ and $w_{\mathrm{pB}}$ are rotating speeds of the hydraulic pumps, and $D_{\mathrm{pA}}^{\mathrm{pA}}$ and $D_{\mathrm{pB}}^{\mathrm{pB}}$ are displacements of the hydraulic pumps, respectively. $C_{\mathrm{t}}$ is calculated parameters as follows: $C_{\mathrm{ipA}}+C_{\mathrm{epA}}+C_{\mathrm{ipB}}+C_{\mathrm{epB}}-C_{\mathrm{im}}-C_{\mathrm{em}}=C_{\mathrm{t}}$

where, $C_{\mathrm{ipA}}, C_{\mathrm{epA}}, C_{\mathrm{ipB}}$ and $C_{\mathrm{epB}}$ respectively are internal and external leakage parameters of pump A and B.

2.2.6 Torque coupling equation

Torque coupling means in the coupling process, the output torque of two power sources is independent from each other, while the output speed must be equal before the dynamic coupling. The final synthetic torque is the superposition of output torque of two power sources. The structure of the coupling gears is as shown in figure 2 .

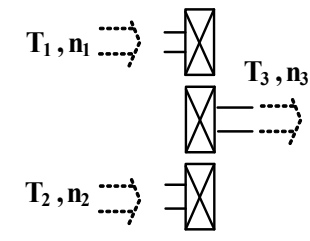

Figure 2 Structure of the coupling gear group

As is shown in figure 2, if the coupling gear group includes three gears, torque and rotating speed of the output gear are $\mathbf{T}_{3}$ and $\mathbf{n}_{3}$, and the corresponding parameters of the input gears are $\mathbf{T}_{1}, \mathbf{T}_{2}, \mathbf{n}_{1}$ and $\mathbf{n}_{2}$. The equations of the torque coupling are as follows:

$\mathbf{n}_{1}=\mathbf{n}_{2}=\mathbf{n}_{3}$

$\mathbf{T}_{1}+\mathbf{T}_{2}=\mathbf{T}_{3}$

Then according to figure 1 , we can get the gear coupling equations of the hybrid system:

$T_{\mathrm{m}}=T_{\mathrm{PB}}+T^{\prime}$

$T_{1}=T^{\prime}+T_{\text {em }}$

where, $T_{\mathrm{m}}$ and $T_{\mathrm{PB}}$ is respectively the torque of the hydraulic motor and hydraulic pump $B, T$ is the transmission torque between the two gear groups, $T_{1}$ is the load torque, and $T_{\mathrm{em}}$ is toque of the electric motor. Then $T_{\text {em }}$ can be derived:

$\left(D_{\mathrm{m}}-D_{\mathrm{pB}}\right) \cdot P_{\mathrm{h}}-\left(J_{\mathrm{m}}+J_{\mathrm{pB}}\right) \cdot \ddot{\theta}_{\mathrm{m}}-\left(B_{\mathrm{m}}+B_{\mathrm{pB}}\right) \cdot \dot{\theta}_{\mathrm{m}}-\left(G_{\mathrm{m}}+G_{\mathrm{pB}}\right) \cdot \theta_{\mathrm{m}}+T_{\mathrm{em}}=T_{1}$

where, $D_{\mathrm{m}}$ and $D_{\mathrm{pB}}$ are displacements of hydraulic motor and pump $\mathrm{B}, J_{\mathrm{m}}$ and $J_{\mathrm{pB}}$ are rotational inertia of hydraulic motor and pump $\mathrm{B}, B_{\mathrm{m}}$ and $B_{\mathrm{pB}}$ are damping coefficients of hydraulic motor and pump B, $G_{\mathrm{m}}$ and $G_{\mathrm{pB}}$ are stiffness values of hydraulic motor and pump B, 
and $\theta_{\mathrm{m}}$ is rotation of the hydraulic motor. In addition, electromagnetic torque of the motor $T_{\mathrm{em}}$ is relative with $\theta_{\mathrm{m}}$.

\subsection{Experimental verification}

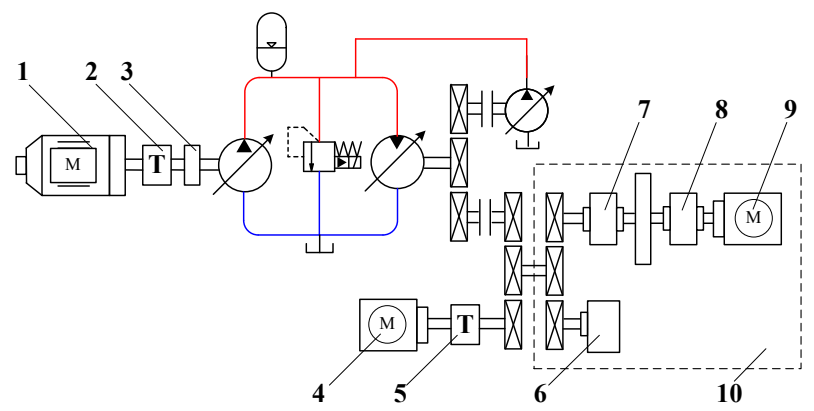

Figure 3 Sketch diagram of the test station

(1). Variable frequency motor. (2). Torque and speed sensor 1. (3). Speed changer. (4). Electromotor 1. (5). Torque and speed sensor 2. (6). Magnetic powder brake. (7). Magnetic powder clutch 1. (8). Magnetic powder clutch 2. (9). Electromotor 2. (10). Load simulation part.

As is shown in figure 3 and 4 , in order to demonstrate the mathematical model above, a test station of the hybrid system is built. In this experiment, a variable frequency motor is selected in order to simulate the wind rotor, and between the variable frequency motor and hydraulic pump there is a torque and speed sensor which can measure the input torque of the simulated power source. That is because in this paper the wind source is considered as a torque-controlled device, and in the experiment the power value of the source is needed. As can be seen of the picture, an electromotor 1 is added in the gear group which is treated as the assisted motor, and a torque and speed sensor is directly connected between them in order to detect the output characteristics of the assisted motor. As is shown from this figure, load of the beam pumping unit is simulated by part 10 . The simulated load should be accordance with the dynamic loading process which is shown in figure 5. One cycle of the dynamic torque of the mechanical load is obtained by regular working equations of beam pumping unit. The simulation method is periodic servo control of the output load torque.

As is shown in figure 4, rated power of the variable frequency motor is $1.2 \mathrm{KW}$, rated power of electromotor $\mathrm{A}$ is $550 \mathrm{~W}$, and rated power of the electromotor $\mathrm{B}$ is $2.2 \mathrm{KW}$. That is because electromotor $\mathrm{B}$ is used for the torque compensation, and in order to ensure the working efficiency of the motor approximately optimal, the rated output power of electromotor B is selected larger, and prepare for future type selection optimization.

Table 1 Several parameter values of the experimental station

\begin{tabular}{cccc}
\hline Parameter & Value & Parameter & Value \\
\hline Depth of plunger $(\mathrm{m})$ & 10000 & Rated power of original motor $(\mathrm{kW})$ & 37 \\
Working fluid level $(\mathrm{m})$ & 600 & Rated power of replaced motor $(\mathrm{kW})$ & 22 \\
Diameter of rod $(\mathrm{mm})$ & 22 & Diameter of pump $(\mathrm{mm})$ & 57 \\
Stroke $(\mathrm{m})$ & 2 & Diameter of tube $(\mathrm{mm})$ & 76 \\
Water cut $(\%)$ & 100 & Frequency of stroke $(1 / \mathrm{min})$ & 6 \\
\hline
\end{tabular}

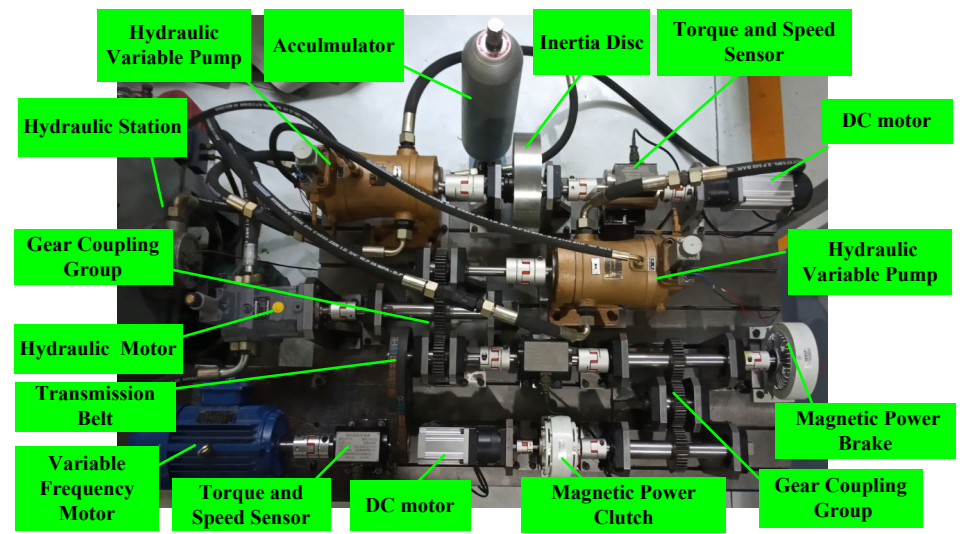

Figure 4 Experimental station of the wind-electric hybrid system

Figure 4 is the experimental station of the windelectric hybrid system according to principle of Figure 3. In the process of the experiments, so as to demonstrate the mathematical model at the same time considering the safety and the common performance of the hydraulic system, displacements of the hydraulic motor and pump are settled stable. The working speed of the hybrid system is set to about 700 RPM to ensure the stability. Torque sensor 2 is adopted to measure the output torque of the beam pumping unit, and the working process of the beam pumping unit is simulated by close-loop controlling its output torque with the feedback of the torque sensor. A group of torque data of the beam pumping unit of model CYJ10-3-37HB is obtained. According to the principle of 
the dynamic torque of the actual project, the control result of the torque is scaled down at the same proportion which can be seen in Figure 5.

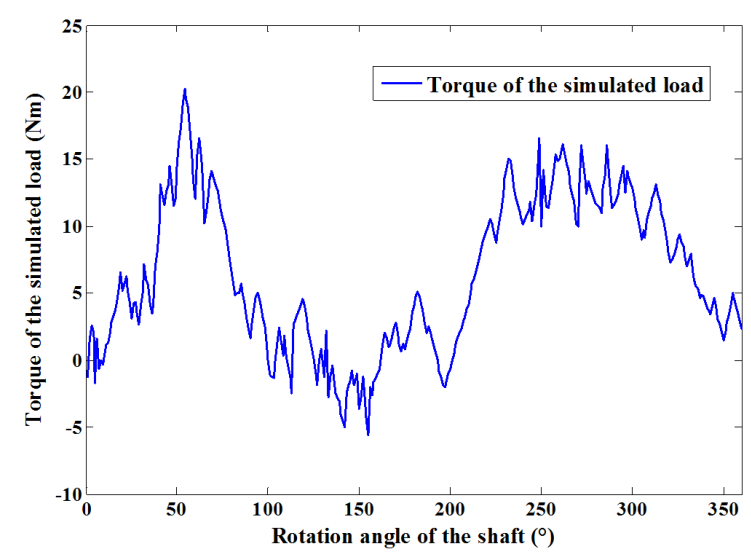

Figure 5 Experimental result of the simulated load torque

Test process:

(1) Start the motor and set all the clutches to the off state;

(2) Adjust the clutch to the closed state to simulate the pumping unit load;

(3) Start the variable frequency motor and adjust the pump displacement to simulate the wind turbine;

(4) All clutches are closed to simulate the windelectric hybrid process.

(5) The experimental data are collected through the test system.

The measurement and control system of the experimental station mainly includes industrial control
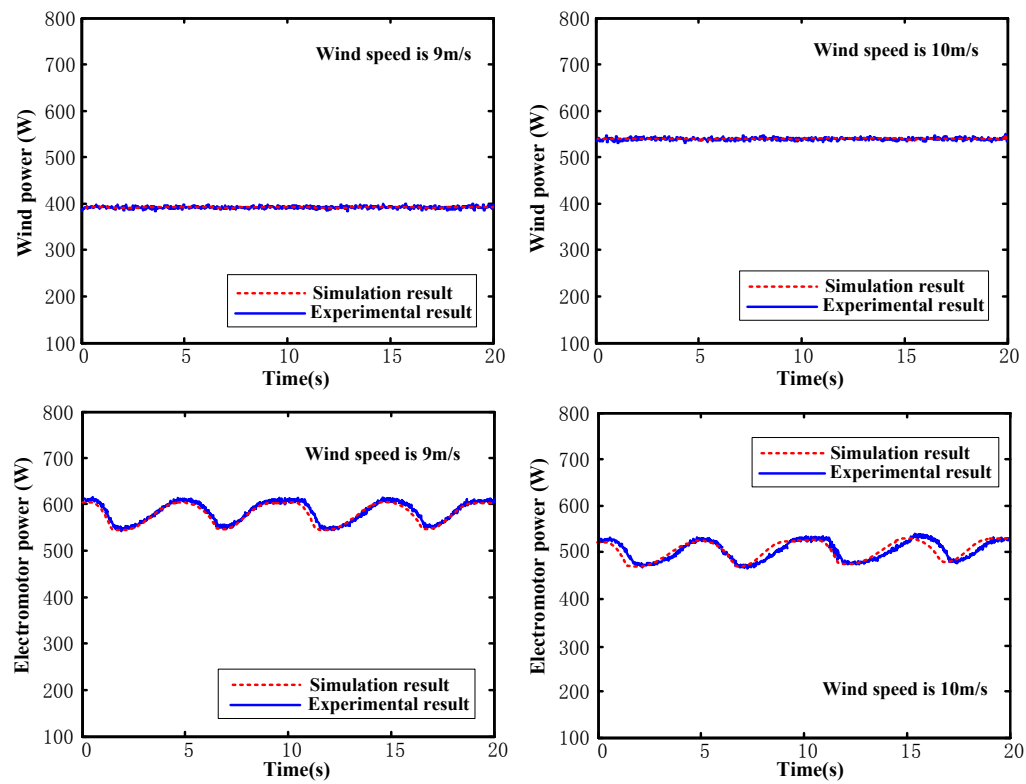

Figure 7 Power contrast curves under different wind speed

3 Wind speed following control method and analysis

According to the application, in order to make the wind wheel work at the optimum velocity ratio under different
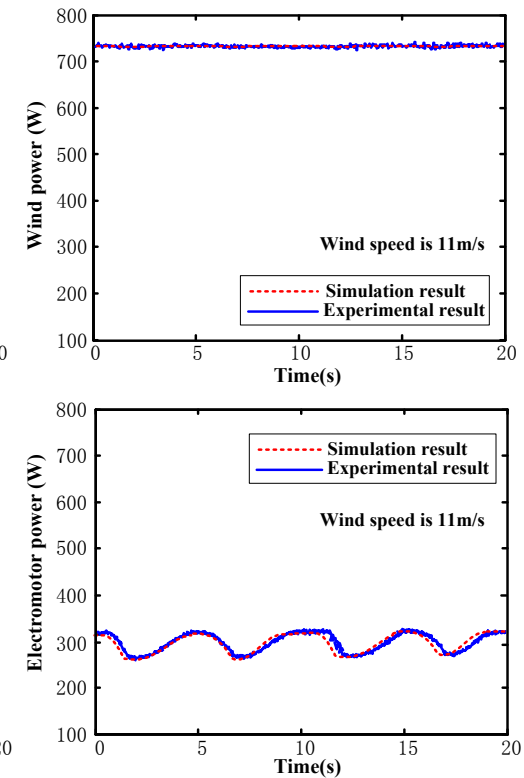

computer (IPC), PCI bus communication, data acquisition card, signal conditioning circuit and control board card. This experimental system uses RTX as the lower machine and Lab Windows as the upper computer. The control cycle of the real-time measurement and control system can reach $0.5 \mathrm{~ms}$. Experimental station control system is shown as Figure 6.

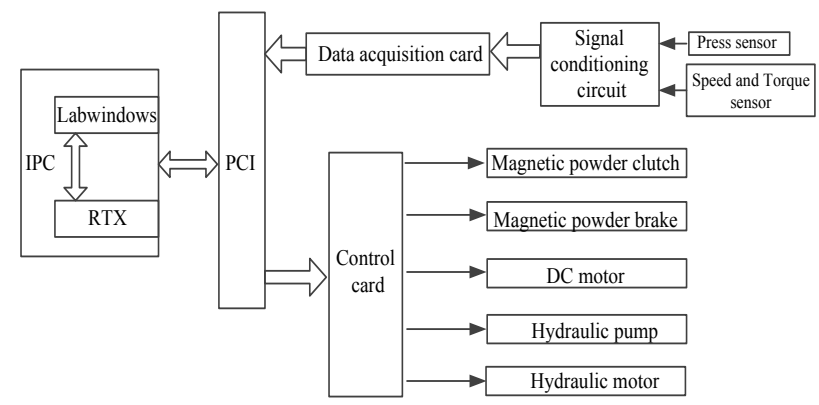

Figure 6 Experimental station control system

The experimental data curve is shown in Figure 7. The motor output power is stable by changing the displacement of pump and hydraulic motor. This helps to the improvement of motor efficiency. When wind speed is $9 \mathrm{~m} / \mathrm{s}$, the output power of the electromotor varies around $580 \mathrm{~W}$. When wind speed is $11 \mathrm{~m} / \mathrm{s}$, the electric power varies around $300 \mathrm{~W}$. Simulation and experiment results indicate the stable output power of the motor is different under different wind speed. The wind power increases, the electric power decreases. The correctness of the mathematical model and energy saving method is verified by numerical simulation and experiment.

wind speed, the optimal working speed of the wind wheel should be controlled so as to get the highest efficiency. The optimal equation is as follows:

$\lambda_{\mathrm{opt}}=\frac{R \cdot \omega_{\mathrm{opt}}}{v}$ 
where, $v$ represents the wind speed, and $w_{\text {opt }}$ is the corresponding optimal angular velocity of the wind wheel, $R$ is the radius of the wind wheel.

Structure of the control system based on feed forward control

As can be seen in Figure 8, main structure of the hybrid power system is a feed forward and closed-loop system. The Feed forward control part is from the wind speed branch current, and the function is expressed as $F_{n}(\mathrm{~s})$. Controlling unit of the hybrid system is expressed as $G(\mathrm{~s})$, and then the basic control principle is as follows.

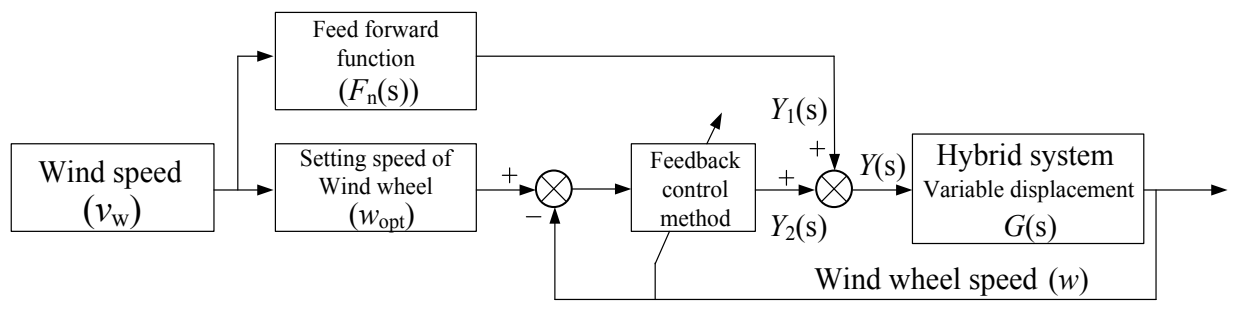

Figure 8 Flow chart of the feed-forward control method of the hybrid system

Dynamic change of the wind speed can be treated as disturbance part, and the feedback control method in the middle part is expressed as $C(\mathrm{~s})$. Therefore, the output function of the wind wheel speed is:

$w=G(s) \cdot Y(s)=G(s) \cdot\left(Y_{1}(s)+Y_{2}(s)\right)$

$Y_{1}(s)=v_{w} \cdot F_{n}(s)$

$e(\mathrm{k})=\omega_{\text {set }}(\mathrm{k})-\omega\left(\mathrm{k}-t_{d} / T\right)$

then, the transfer function from the disturbance part to the output part is:

$\frac{w}{v_{w}}=\frac{\left(F_{n}(s)+w_{o p t} C(s)\right) \cdot G(s)}{1+G(s) \cdot C(s)}$

then the error transfer function is:

$\frac{v_{w} \cdot w_{o p t}-w}{v_{w} \cdot w_{o p t}}=\frac{w_{o p t}-F_{n}(s) \cdot G(s)}{w_{o p t}(1+G(s) \cdot C(s))}$

If the error is controlled to zero, then $w_{o p t}-F_{n}(s) \cdot G(s)$ $=0$.

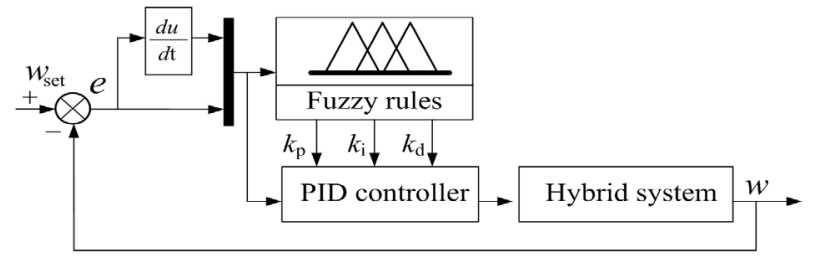

Figure 9 Diagram of the fuzzy-PID control system

The fuzzy-PID part is shown in Figure 9. The hybrid system is directly controlled by $P_{w}$, and $P_{w}$ can be calculated by the following equations:

$$
\begin{aligned}
& D_{w}(\mathrm{k})=D_{i n}+D_{c o m}(\mathrm{k}) \\
& D_{c o m}(\mathrm{k})=k_{\mathrm{p}} e(\mathrm{k})+k_{\mathrm{i}} T \sum_{j=0}^{k} e(\mathrm{j})+k_{\mathrm{d}}(e(\mathrm{k})-e(\mathrm{k}-1)) / T \\
& e(\mathrm{k})=\omega_{s e t}(\mathrm{k})-\omega\left(\mathrm{k}-t_{d} / T\right)
\end{aligned}
$$

where $e$ is the error of the control signal, $k$ is the step number, $T$ is sampling time, $P_{i n}$ is the settled initial pulse width, and $P_{\text {com }}$ means the pulse width compensation.

\subsection{Fuzzy rules}

The fuzzy rules are self-adjusted according to the fuzzy relations between $k_{\mathrm{p}}, k_{\mathrm{i}}, k_{\mathrm{d}}$, and $e, e_{\mathrm{c}}$. Fuzzy outputs are $k_{\mathrm{p}}^{\prime}$, $k_{\mathrm{i}}^{\prime}, k_{\mathrm{d}}^{\prime}$, and:

$k_{p}^{\prime}=\left(k_{p}-k_{p \min }\right) /\left(k_{p \max }-k_{p \min }\right)$

$k_{i}^{\prime}=\left(k_{i}-k_{i \min }\right) /\left(k_{i \max }-k_{i \min }\right)$

$k_{d}^{\prime}=\left(k_{d}-k_{d \min }\right) /\left(k_{d \text { max }}-k_{d \text { min }}\right)$

Where, $k_{\mathrm{p} \text { min }}$ means the minimum value of $k_{\mathrm{p}}$, and $k_{\mathrm{pmax}}$ means the maximum value. In addition, $k_{\mathrm{p}}^{\prime}, k_{\mathrm{i}}^{\prime},{ }^{\mathrm{p}}{ }_{\mathrm{d}}, \in[0,3]$.

Fuzzy adjustment tables of $k_{\mathrm{p}}^{\prime}, k_{\mathrm{i}}^{\prime}, k_{\mathrm{d}}^{\prime}$ are shown as the following table. As shown in Table 2, NB, NM, NS, ZO, PS, $\mathrm{PM}$ and $\mathrm{PB}$ mean negative big, negative middle, negative small, zero, positive small, positive middle and positive big, respectively. In addition, as is shown in figure 10 and 11, it is the fuzzy membership functions.

Table 2 Diagram of the fuzzy-PID control system

\begin{tabular}{cccccccc}
\hline NB & PB & PB & PB & PS & PS & PS & PS \\
NM & PM & ZO & PB & PB & PB & PS & PS \\
NS & PM & ZO & PB & PB & PB & PS & PS \\
ZO & PM & ZO & PB & PB & PB & PB & PS \\
PS & PM & ZO & ZO & PB & PB & PB & PB \\
PM & PM & PM & ZO & PB & PB & PB & PB \\
PB & ZO & PM & PM & PM & PM & PM & PM \\
\hline
\end{tabular}

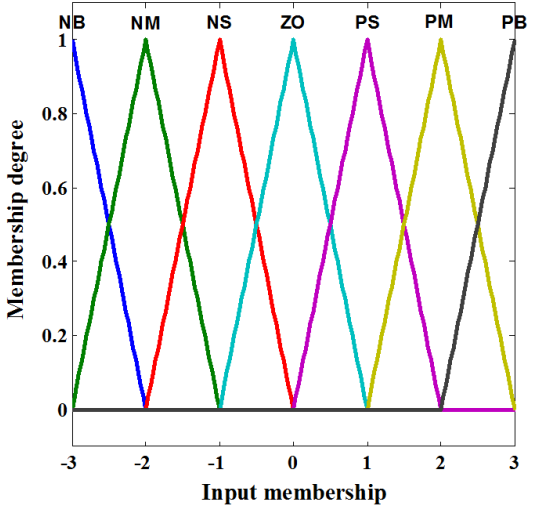

Figure 10 Fuzzy membership function of the input parameter 


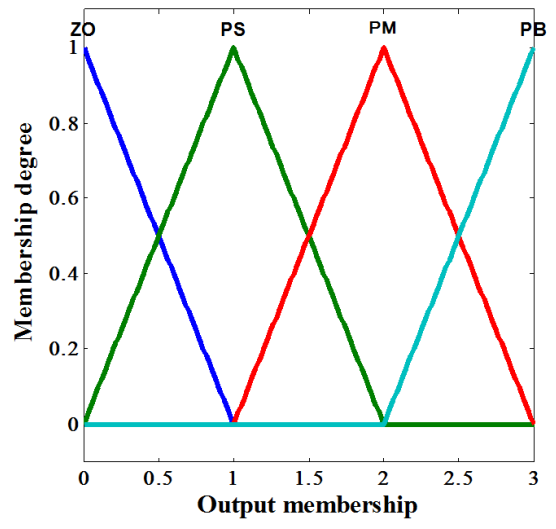

Figure 11 Fuzzy membership function of the output parameter

\section{Control analysis}

In order to analyze the control effect of the feed forward control, the results are compared with the traditional PID control method. According to the actual measurement of the dynamic wind speed, frequency of the wind is set to

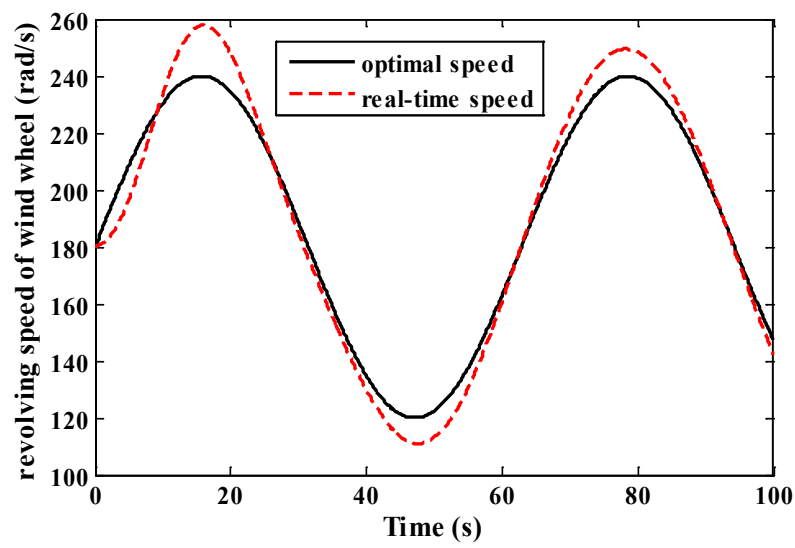

Figure 12 PID control method (Frequency is $0.1 \mathrm{~Hz}$, and Amplifier is $3 \mathrm{~m} / \mathrm{s}$ )

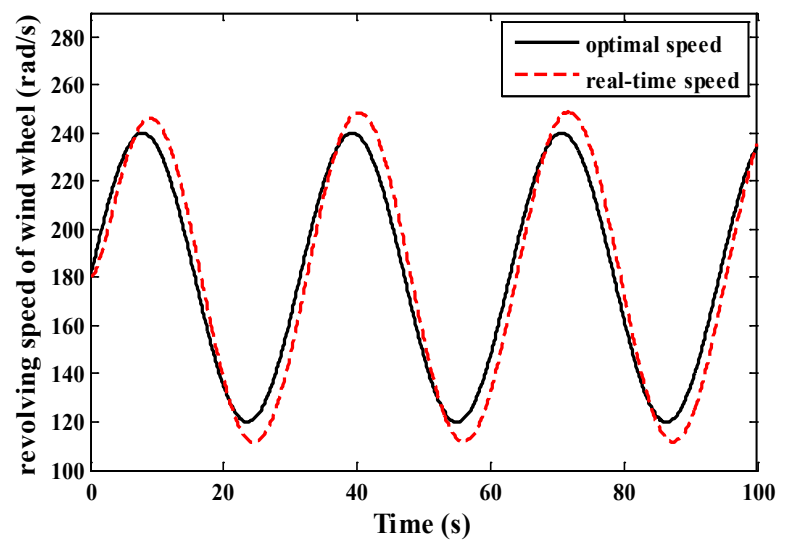

Figure 14 PID control method (Frequency is $0.2 \mathrm{~Hz}$, and Amplifier is $3 \mathrm{~m} / \mathrm{s}$ )
$0.1,0.2,0.3$, and $0.5 \mathrm{~Hz}$, and amplifier of the wind is set to 1,3 , and $5 \mathrm{~m} / \mathrm{s}$.

When the frequency of the wind speed is set to $0.1 \mathrm{~Hz}$, and the amplifier is $3 \mathrm{~m} / \mathrm{s}$, then the frequency is relatively low, and the amplifier is relatively small. As is shown in Figure 12, when the hybrid control system applies the normal PID method, the highest over shoot of the revolving speed of the wind wheel is over $40 \%$, and the control result curve slightly lags behind the control signal. However, as is shown in Figure 13, when the feed forward control method is applied, the overshoot basically disappears, and the lag hardly exist, which shows good control following features.

In the real application, when variation of the wind speed is higher, in the simulation the frequency of the wind speed is set to $0.2 \mathrm{~Hz}$, and the amplifier is $3 \mathrm{~m} / \mathrm{s}$. As is shown in Figure 14, when the frequency is relatively high, and the system is controlled by PID control method, the overshoot is about $30 \%$, and the lag behind the control signal is about 2 seconds. As is shown in Figure 15, it can be seen that the overshoot is greatly reduced, and the control result curve lag is eliminated.

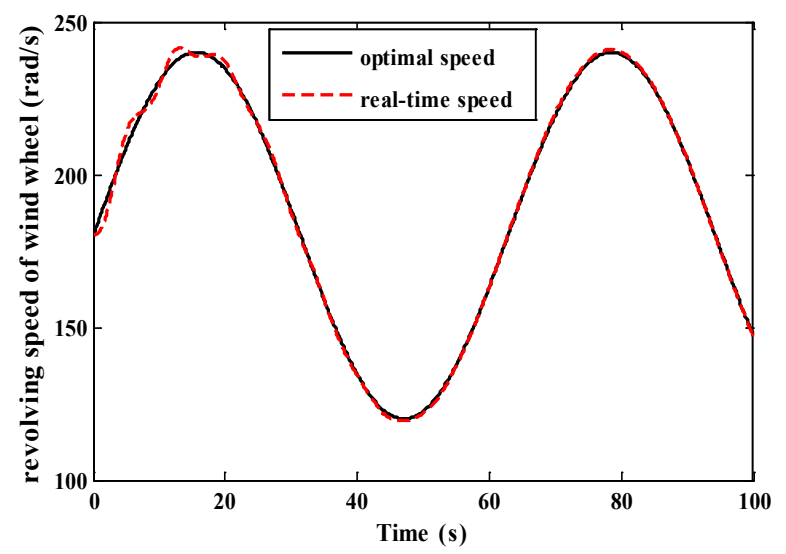

Figure 13 Feed forward control method (Frequency is $0.1 \mathrm{~Hz}$, and Amplifier is $3 \mathrm{~m} / \mathrm{s}$ )

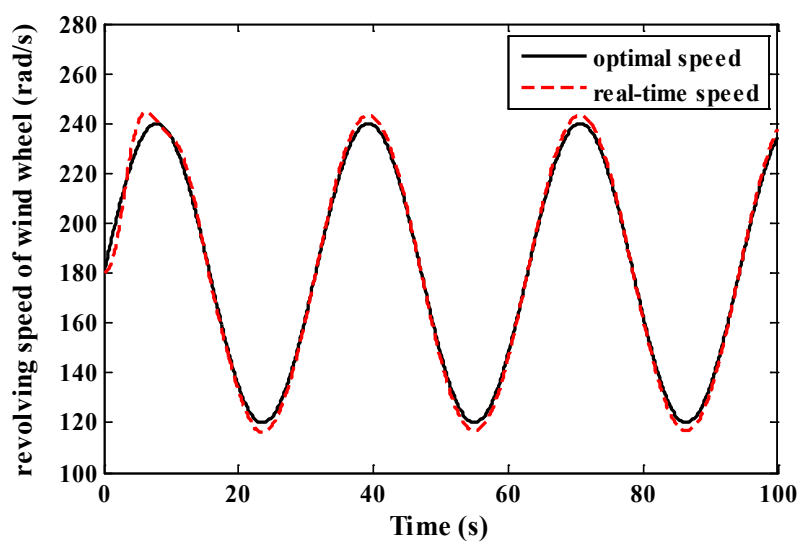

Figure 15 Feed forward control method (Frequency is $0.2 \mathrm{~Hz}$, and Amplifier is $3 \mathrm{~m} / \mathrm{s}$ ) 


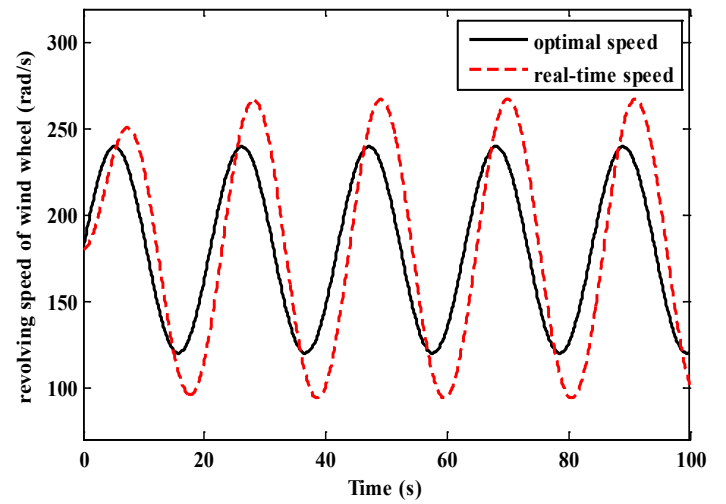

Figure 16 PID control method (Frequency is $0.3 \mathrm{~Hz}$, and Amplifier is $3 \mathrm{~m} / \mathrm{s}$ )

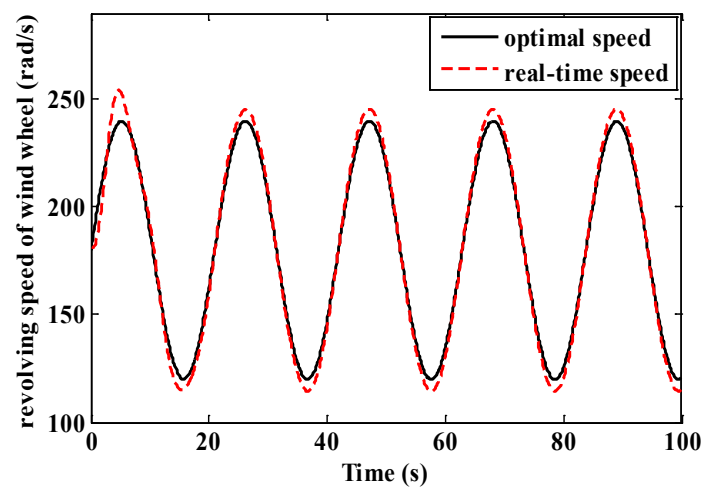

Figure 17 Feed forward control method (Frequency is $0.3 \mathrm{~Hz}$, and Amplifier is $3 \mathrm{~m} / \mathrm{s}$ )

When the frequency of the wind speed is set to $0.3 \mathrm{~Hz}$, and the amplifier is $3 \mathrm{~m} / \mathrm{s}$, from Figure 16 it can be seen that under the PID control method the overshoot is much serious which can be up to over $50 \%$. In addition, the output signal lags behind the control signal by 4 seconds to the maximum. In the real application, when the output speed can hardly follow the control signal, the efficiency will always be at a low condition. However, the feed forward control method can greatly solve this problem. In Figure 17, when the feed forward control method is applied, the control overshoot can be reduced by 3over $80 \%$. In addition, the lag can also be eliminated, too.

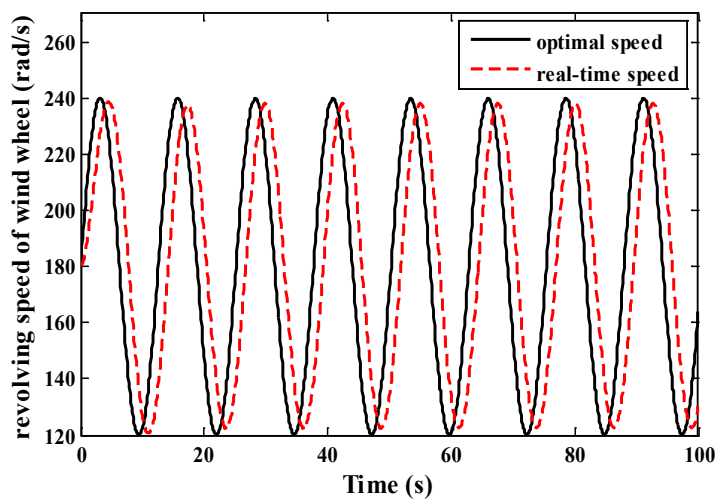

Figure 18 PID control method (Frequency is $0.5 \mathrm{~Hz}$, and Amplifier is $3 \mathrm{~m} / \mathrm{s}$ )

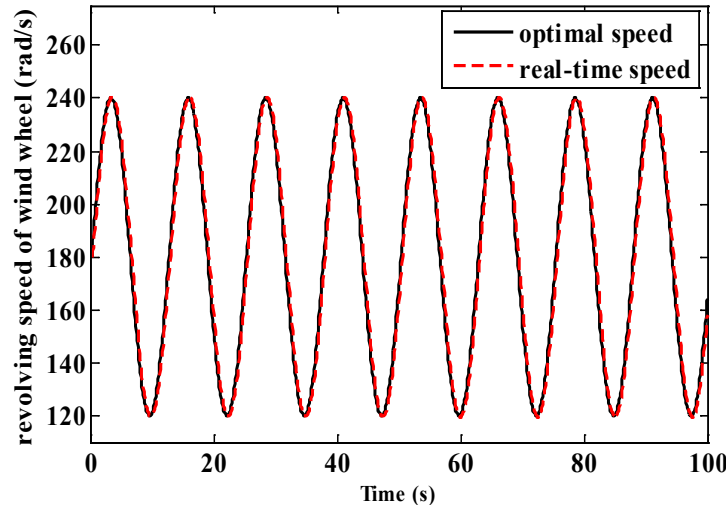

Figure 19 Feed forward control method (Frequency is $0.5 \mathrm{~Hz}$, and Amplifier is $3 \mathrm{~m} / \mathrm{s}$ )

The highest real frequency of the wind speed can up to $0.5 \mathrm{~Hz}$. When the frequency of the wind speed is set to $0.5 \mathrm{~Hz}$ and the amplifier is $3 \mathrm{~m} / \mathrm{s}$, the PID control method shows a significant lag between the control and output signals. The lagging time is about 2 seconds, so it accounts for about $35 \%$ of the whole period. This paper applies feed forward control method, and it obviously solves the lagging problem, the follow-through level reaches a good level.

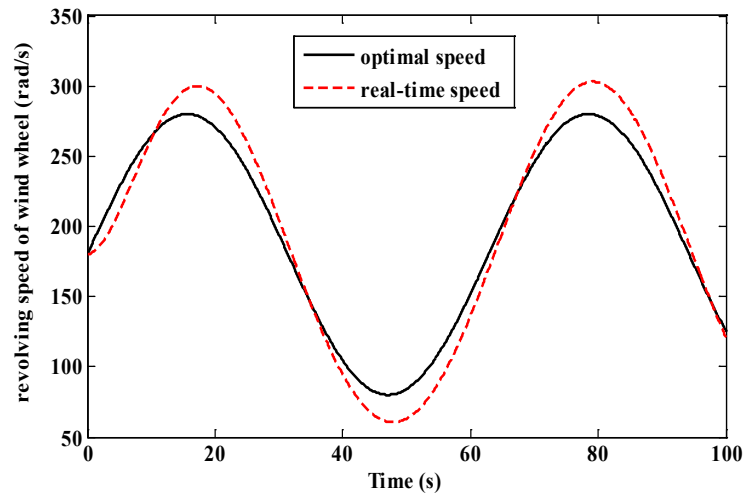

Figure 20 PID control method (Frequency is $0.1 \mathrm{~Hz}$, and Amplifier is $5 \mathrm{~m} / \mathrm{s}$ )

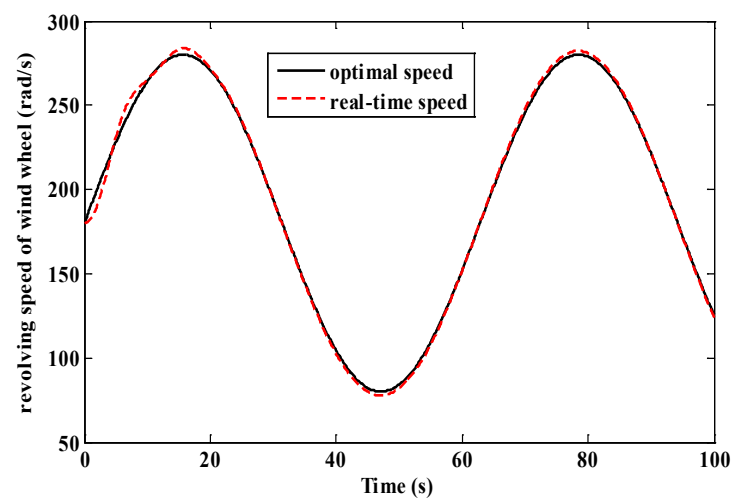

Figure 21 Feed forward control method (Frequency is $0.1 \mathrm{~Hz}$, and Amplifier is $5 \mathrm{~m} / \mathrm{s}$ )

When the amplifier is set relatively high to $5 \mathrm{~m} / \mathrm{s}$, through PID control method it mainly appears overshoot 
and lagging problem. The overshoot value is about $25 \%$, however, the lagging problem is not very serious. From Figure 22, the Feed forward control method can greatly solve the overshoot problem.

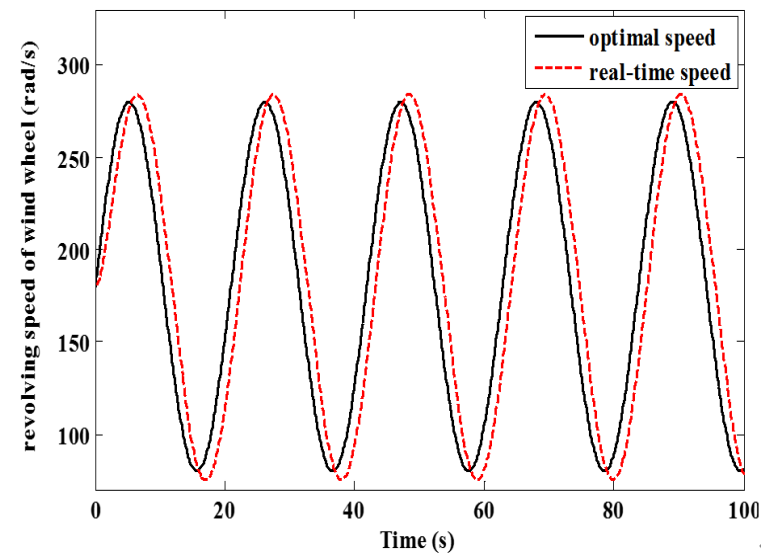

Figure 22 PID control method (Frequency is $0.3 \mathrm{~Hz}$, and Amplifier is $5 \mathrm{~m} / \mathrm{s}$ )

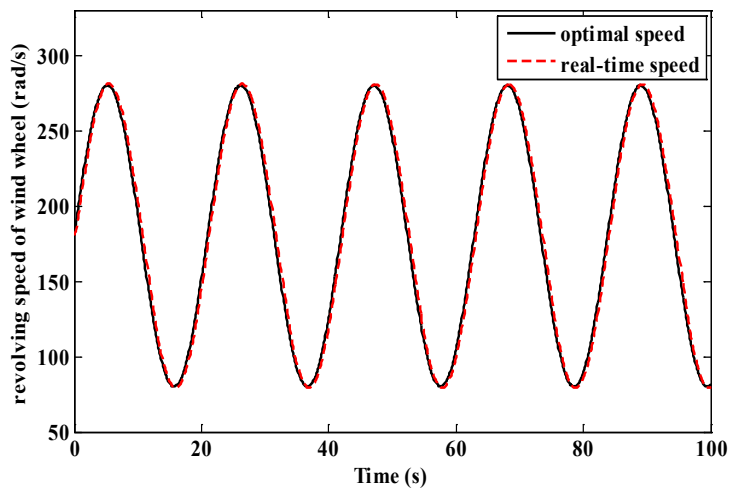

Figure 23 Feed forward control method (Frequency is $0.3 \mathrm{~Hz}$, and Amplifier is $5 \mathrm{~m} / \mathrm{s}$ )

When the frequency is relatively high and the amplifier is high, too, lagging time with the PID control method is approximately $20 \%$. From Figure 23 , the Feed forward control method can also solve the lagging problem, which is the same as the above results.

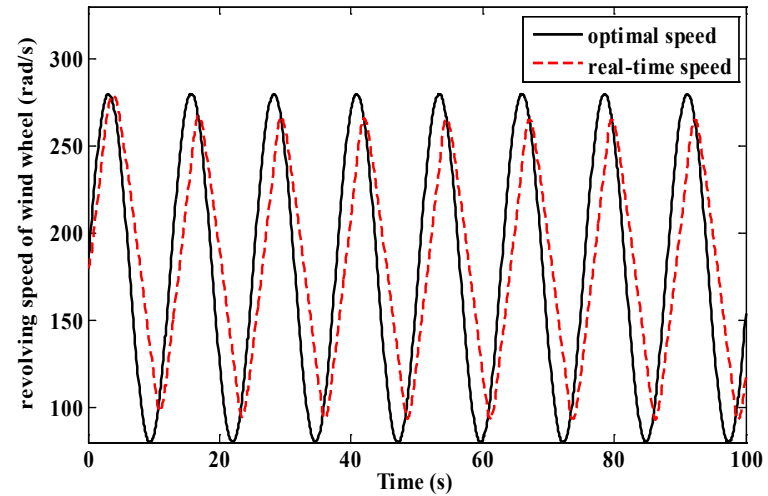

Figure 24 PID control method (Frequency is $0.5 \mathrm{~Hz}$, and Amplifier is $5 \mathrm{~m} / \mathrm{s}$ )

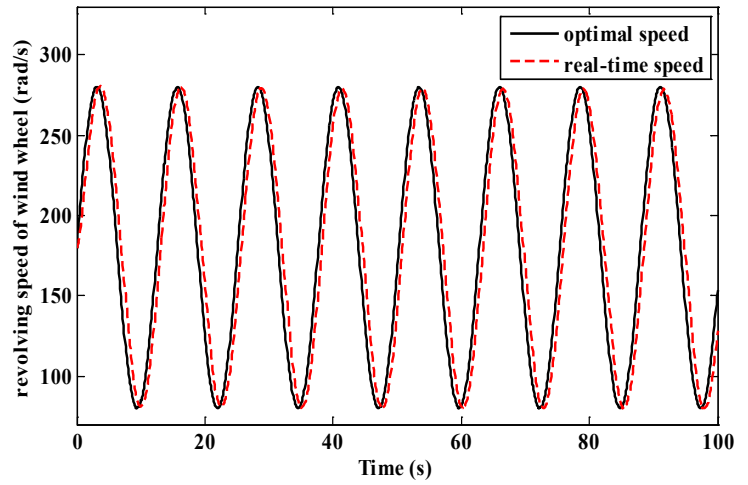

Figure 25 Feed forward control method (Frequency is $0.5 \mathrm{~Hz}$, and Amplifier is $5 \mathrm{~m} / \mathrm{s}$ )

When the frequency is $0.5 \mathrm{~Hz}$ and the amplifier is $5 \mathrm{~m} / \mathrm{s}$, the dynamic control characteristics show poor performance with traditional PID control. Furthermore, the real-time speed can not reach the amplifier of the optimal speed, and the phase position of the output speed greatly lags behind the optimal signal. As is shown in Figure 25, the feed forward control method can obviously reduce the lag. What is more, precisely the real-time speed can also follow the optimal signal.

\section{Conclusion}

This paper provides a control method of wind power hydraulic-motor hybrid power system of beam pumping unit based on feed-forward control in order to improve the wind energy efficiency by controlling the revolving speed of wind wheel to follow the optimal control speed. Mathematical model of the wind power hydraulic-motor hybrid power system is built, and experimental station of the hybrid system is setup to verify the mathematical model. Wind speed following control method is analyzed by simulation which can be concluded that: to begin with, according to the experiment results, the mathematic model is proved to be effective; next, simulation studies show that the proposed feed-forward control method can improve the response rate as well as reduce the response lag. This research can be a reference for the application of the feedforward control method on the hybrid power system of beam pumping unit.

Conflict of Interest: The authors declare that they have no competing interests.

Acknowledgments: This project was supported by the Science Research Foundation of Inner Mongolia University for the nationalities grant no.NMDGP1704 the Inner Mongolia nature Science Foundation (grant no.2016MS0622) National nature Science Foundation grant no.51865046,Science and technology innovation leading project of Inner Mongolia grant no.KCBJ2018028.

\section{References}

[1] M.Z..; et al. The Detailed Calculation Model of the Friction between Sucker Rod and the Liquid in the Sucker Rod 
Pump Lifting System of Heavy Oil. Applied Mechanics \& Materials,2014, 694.1:346-349.

[2] S.W.;et al. The design and simulation of beam pumping unit.. International Conference on Automation and Computing IEEE, 2015:1-4.

[3] L.Y.; et al. A Multifunction Energy-Saving Device With a Novel Power-Off Control Strategy for Beam Pumping Motors. IEEE Transactions on Industry Applicatio ns,2011,47.4:1605-1611.

[4] D.S.; et al. The Dynamic Simulation Model and the Comprehensive Simulation Algorithm of the Beam Pumping System. International Conference on Mechanical and Automation Engineering IEEE, 2013:118122.

[5] G. S.G.; D.L. M. Inferring power consumption and electrical performance from motor speed in oil-well pumping units. Petroleum and Chemical Industry Conference, 1995. Record of Conference Papers. Industry Applications Society IEEE, 1997:277-283.

[6] L. H.Q; et al. An Energy Saving System for a Beam Pumping Unit. Sensors (Basel, Switzerland) 16.5(2016):685.

[7] L. H.; K.L. S; P. G. M.. Neural-network-based sensorless maximum wind energy capture with compensated power coefficient."IEEE transactions on industry applications
41.6 (2005): 1548-1556.

[8] S. Y.;S.K.; M. B.. Feedback linearization control based particle swarm optimization for maximum power point tracking of wind turbine equipped by PMSG connected to the grid. International journal of hydrogen energy 41.45 (2016): 20950-20955.

[9] R. H.; et al. A novel constant output powers compound control strategy for variable-speed variable-pitch wind turbines. IEEE Access 6 (2018): 17050-17059.

[10] J. C., C.J., and Chunying Gong. Constant-bandwidth maximum power point tracking strategy for variablespeed wind turbines and its design details. IEEE Transactions on Industrial Electronics 60.11 (2012): 5050-5058.

[11]A.K.; A. G.; et al. Current controller design for DFIGbased wind turbines using state feedback control. IET Renewable Power Generation (2019).

[12] L.J.; et al. Feedforward transient compensation control for DFIG wind turbines during both balanced and unbalanced grid disturbances. IEEE Transactions on Industry Applications 49.3 (2013): 1452-1463.

[13] V. N. W.;G. J.; and J. W.. Predictive control of an experimental wind turbine using preview wind speed measurements. Wind Energy 18.3 (2015): 385-398. 